\title{
TWO-DIMENSIONAL MATHEMATICAL MODEL OF FLOWS IN THIN FILM COMPOSITE MEMBRANES
}

\section{Aatma Maharajh ${ }^{1}$, Prakash Persad ${ }^{2}$, Denver Cheddie ${ }^{3}$ and Edward Cumberbatch $^{4}$}

\author{
${ }^{1,2,4}$ Design and Manufacturing Systems, The University of Trinidad and Tobago, Trinidad and \\ Tobago \\ ${ }^{3}$ Utilities Engineering Group, The University of Trinidad and Tobago, Trinidad and Tobago \\ ${ }^{1}$ Email: aatma.maharajh@utt.edu.tt*(Corresponding author) \\ ${ }^{2}$ Email: prakash.persad@utt.edu.tt \\ ${ }^{3}$ Email: denver.cheddie@utt.edu.tt \\ ${ }^{4}$ Email: edward.cumberbatch@utt.edu.tt
}

\begin{abstract}
Mathematical modelling of reverse osmosis membranes has evolved from simplified one-dimensional simulations to complex three-dimensional simulations using CFD based techniques. These models have been useful in simulating solute and solvent flows across the membrane, the development of the concentration polarisation layer and the effects of spacer and spacer geometry as some examples. Various simplifying assumptions are, however, made in the modelling process that limit their extension to the specific application of directly-coupled wave powered desalination. These include the treatment of the membrane and use of rejection coefficients for solute transport. The model presented in this paper addresses some of the limitations imposed currently on available models. Fully coupled mass-momentum equations are specified for the hydrodynamics within the feed, membrane and permeate channels. Semi-empirical relationships are developed to account for the effects of inlet pressure, cross-flow velocity and inlet concentration on solvent and solute flows across the membrane. The model is validated against published experimental data and the predicted errors for simulations of solvent and solute flows were found to be $0.6 \%$ and $0.7 \%$ respectively. The effects of three feed spacer types, submerged, cavity and zigzag, on solvent and solute flows are then considered. Larger wall shear stress was seen for the submerged type spacer than for either cavity or zigzag types.
\end{abstract}

Keywords: Computation Fluid Dynamics, Concentration Polarisation, Diffusion Coefficients, Reverse Osmosis, TFC membranes

https://doi.org/10.47412/GAEH3878

\section{Introduction}

Numerous mathematical models have been developed to characterise the reverse osmosis process [1-8]. These models can be broadly classified as either being analytical or numerical [9]. Independent of the classification, three areas must be considered when modelling the reverse osmosis process: (i) solute and solvent flows across the membrane; (ii) the effects of concentration polarisation and (iii) the hydrodynamics within the feed and permeate channels. The coupled nature of these areas has contributed to the complexity of the models that have been developed to accurately simulate the process. Although some models vary in their treatment of solvent and solute transport across the membrane, the governing equations are similar 
[10]. The equations for solvent and solute flows posit a linear relationship between solvent and solute flows and their respective driving potentials, pressure and concentration, although in practice this is not the case [3, 4, 11-15]. Zhou \& Song [14] presented experimental data on the increasing non-linear behaviours for both solvent and solute flows for increasing salt concentrations.

Considering solvent flows, Paul [13] noted that the linear relationship was untenable since the concentration gradient induced by the pressure difference must be bounded; a flaw that arises because of the subtle simplification implied in the derivation of solvent flow. Additionally, the assumption of a constant water permeability carried inaccuracies since it is affected by experimental variables such as $\mathrm{pH}$, pressure and ionic strength [16]. In the instance of non-linearity of solute flows, limits to solute rejection have been noted in the literature $[14,17]$. Assuming that the primary mechanism of solute transport through the active layer is diffusive, the diffusion coefficient is inherent to the diffusing material and can be affected by parameters such as viscosity, temperature and concentration [18-19]. Additionally, Countinho [20] noted that the increase in pressure resulted in a greater convection rate for the transport of solute to the membrane surface. This increases the concentration at the interface, causing an increase in the diffusivity of the solute in the opposite direction to that of the process pressure.

Concentration polarisation is a phenomenon where solute rejected by the membrane forms a layer of high concentration near the surface of the membrane, reducing the solvent flow across the membrane [21-23]. Various approaches have been proposed to estimate the concentration at the membrane surface [21, 23-27]. These models typically introduce a rejection coefficient to represent the selectivity of the membrane, opting to treat the membrane as a homogenous material. Most models do not take into account the various layers that comprise the membrane, though there have been some limited attempts at characterising the role played by the individual layers $[17,28]$. There is a belief that the porous support structure may contribute significantly to the diffusive transport through the composite structure. The ratio of "real" (effective) flow and "ideal" flow is identical to the inverse ratio of the "ideal" and "real" diffusive path lengths [17]. This model however assumes that the porous support is comprised of uniform cylindrical pores, which in practice is not necessarily the case.

The hydrodynamics within the feed channel is affected by the feed spacer arrangement used. Feed spacers are typically composed of two sets of straight non-woven parallel cylindrical filaments [29]. Feed spacers form integral parts of reverse osmosis (RO) spiral wound modules for two purposes. Firstly, feed spacers keep membranes apart from the flow channel. Secondly, feed spacers promote mixing of the fluid, hence reducing the effects of concentration polarisation [30]. The use of computational fluid dynamics (CFD) based techniques has further enhanced our understanding of the hydrodynamics within the feed and permeate channels. Various authors have and continue to publish on the effects of feed spacers on solute and solvent flows through the membrane [31]. Broadly speaking, spacer models typically exclude permeation as this has little effect on wall shear stress [32], though examples are found in the literature [3940]. Calculation of local permeate flows can increase computational load.

The mathematical model presented in this paper addresses the non-linear behaviour of solvent and solute flows across the membrane, concentration polarisation and the hydrodynamics within the feed and permeate channels. Fully coupled mass-momentum equations are used to define the hydrodynamics within the feed and permeate layers. Equations are specified for solute transport though the individual layers that comprise thin-film membrane. Further, consideration is given to the effects of inlet pressure, cross-flow velocity and concentration on solvent and solute flows across the membrane. Simulations were run for the effects of feed spacers on permeation through the membrane. It is noted that the work presented in this paper forms part of ongoing research into directly coupled wave-powered desalination [35-36]. The consideration of existing limitations is of significant importance to modelling this process. 


\section{Model Development}

The basic model equations were previously presented in Maharajh \& Persad [35]. As further modifications were made to the original model and for ease of reference, they are presented anew.

\subsection{Fluid and Solute Flow in the Feed and Permeate Channels}

The governing equations for fluid and solute flows within the feed and permeate channels are given by the conservative two-dimensional forms of the continuity and Navier-Stokes equations and transport equations respectively. Fluid flow within these channels are assumed to be within the laminar regime, the fluid is assumed to be completely incompressible with constant viscosity. Buoyancy forces are assumed to be negligible, which is suitable for short channels flows [5]. Solute flows are assumed to have constant diffusivity within these channels. The system is also assumed to be isothermal.

For flow in narrow empty channels, laminar flows are assumed for Reynolds number, Re, less than 2000 [37]. It is reported in the literature that there is departure from the laminar flow regime at very low Reynolds numbers for spacer filled channels [38-39]. This modified Reynolds number, $\mathrm{Re}_{\mathrm{m}}$, is defined on the basis of superficial velocity and spacer filament diameter. Laminar regime persists for $\mathrm{Re}_{\mathrm{m}}<200$ [38-39]. Manufacturers prescribe that the average velocity and pressure drop for spacer filled channels do not exceed $0.34 \mathrm{~ms}^{-1}$ and $0.6 \mathrm{bar} / \mathrm{m}$; this corresponds to Reynolds number, defined on a similar basis, of less than 200 [38]. For all simulations, laminar flows are, therefore, prescribed for both spacer free and spacer filled channels.

\subsection{Fluid Flow through the Membrane}

The permeate flow, $J_{w}$, across the active and porous support layers of the membrane is given by the Eq. (1):

$$
J_{w}=A(1+\alpha)\left(\Delta P-\frac{1}{(1+\alpha)} \Delta \pi\right)
$$

Equation 1 is a modified version of the equation for permeate flow derived in solution-diffusion model [2]. The membrane is similarly assumed to be non-porous. $A$ is the pure water permeability, $\alpha$ is a dimensionless semi-empirical relationship that accounts for the effects of pressure, cross-flow velocity of the solute and concentration on solvent flow through the membrane. $\Delta P$ is the hydraulic pressure differential across the membrane. It is calculated using the pressure in the feed channel at the membrane surface, $P_{f, m}$, and the pressure in the permeate channel at the membrane surface, $P_{p, m}$. Pressure decreases moving along the membrane surfaces as a result of frictional losses across the channel. As such, $\Delta P$ must be calculated for the length of the membrane. It is given by the Eq. (2):

$$
\Delta P=P_{f, m}[0 \rightarrow L, 0]-P_{p, m}[0 \rightarrow L, h 1+h 2]
$$

$\Delta \pi$ is the osmotic pressure differential across the active and porous supports layers of the membrane. It is calculated using the concentration in the feed channel at the membrane surface, $c_{f, m}$, and the concentration in the permeate channel at the membrane surface, $c_{p, m} . \Delta \pi$ must be calculated for the length of membrane. It is estimated using Van't Hoff approximation for osmotic pressure of low concentration solutions and is given by Eq. (3):

$$
\Delta \pi=\emptyset R T\left(c_{f, m}[0 \rightarrow L, 0]-c_{p, m}[0 \rightarrow L, h 1+h 2]\right)
$$

Equation 1 includes a semi-empirical relationship that accounts for the effects of inlet pressure, inlet concentration and cross-flow velocity of solutes on solvent across the membrane which is not typically included in the derivation of equations for solvent flows $[3,5,12-16]$. The introduction of the semi- 
empirical coefficient within the equation for solvent flow applies only to the hydraulic pressure differential term. Consider the following. The equation used to calibrate pure water permeability coefficient, $A$, is given by Eq. (4) [31].

$$
J_{w}=A \Delta P
$$

In the absence of any concentration, variability of solvent permeation would be as a direct result of inlet pressure. As average cross-flow velocities are a direct result of the pressure differential across the feed channel, this effect is taken into account in Eq. (4) through the calculation of $\Delta P$. The application of the semi-empirical relations is as shown in Eq. (5).

$$
J_{w}=A \Delta P+\alpha A \Delta P
$$

Where now a concentration gradient exists, pressure induces the concentration gradient across the membrane [14]. Consideration for the effects of the crossflow velocity and concentration of the solute must be given. They enter into the equation via the semi-empirical relationship. These are seen as "impedances/admittances" towards solvent flow. Eq. (5) is rewritten as shown.

$$
J_{w}=A \Delta P+\alpha A \Delta P-A \Delta \pi=A(1+\alpha)\left(\Delta P-\frac{1}{(1+\alpha)} \Delta \pi\right)
$$

Corrections to the osmotic pressure differential are introduced through calculations of the concentration gradient across the membrane.

\subsection{Salt Flows through the Membrane}

Salt rejection within the membrane is assumed to occur only in the active layer of the membrane. Within the active layer of the membrane, solute transport is assumed to be completely diffusive, consistent. Solute transport is given by Eq. (7):

$$
(1+\beta) D_{s(m)}\left(\frac{\partial^{2} c_{m}}{\partial x^{2}}+\frac{\partial^{2} c_{m}}{\partial y^{2}}\right)=0
$$

$\beta$ is a dimensionless semi-empirical relation that accounts for the effects of inlet pressure on solute flow through the active layer of the membrane. It is noted that at significantly higher average cross-flow velocities, there may be convection of solute from the polarisation layer [21]. This is not considered in this model. Salt flow transport in the porous support is given by the steady-state conservative form of the convection-diffusion equation, Eq. (8):

$$
u \frac{\partial c_{p s}}{\partial x}+v \frac{\partial c_{p s}}{\partial y}=D_{s(p s)}\left(\frac{\partial^{2} c_{p s}}{\partial x^{2}}+\frac{\partial^{2} c_{p s}}{\partial y^{2}}\right)
$$

\subsection{Boundary Conditions}

\subsubsection{Fluid Flow}

The pressure and velocity at the feed inlet and outlet are given by the following:

$\begin{array}{cc}\text { Feed Inlet } & \text { Feed out } \\ p(0,0 \rightarrow h 1)=p_{\text {in }} & \mathrm{v}(L, 0 \rightarrow h 1)=v_{\text {out }}\end{array}$

At the membrane walls, the velocity is constrained perpendicular to the membrane. Depending on the configuration of the membrane, the velocity components at the wall are given by:

$\begin{array}{cc}\text { Top of feed channel } & \text { Bottom of Feed Channel } \\ u\left(0 \rightarrow L, y_{h 1}\right)=0 & u(0 \rightarrow L, 0)=0\end{array}$




$$
v\left(0 \rightarrow L, y_{h 1}\right)=0 \quad v(0 \rightarrow L, 0)=J_{w}
$$

At the porous support layer and permeate channel interface, fluid flow is again constrained perpendicular to the porous support layer. At the permeate outlet, pressure is set to atmospheric.

\subsubsection{Solute Flow}

The concentration at the inlet is set to:

$$
c(0,0 \rightarrow h 1)=c_{\text {in }}
$$

Solute flow is convected at the same rate as the fluid flow within the feed and permeates channels. Within the membrane, solute flow is convected only in the porous layer:

$$
\begin{array}{cc}
\text { Feed/Permeate Channels } & \text { Membrane Channel } \\
u_{s}=u_{f / p} & u_{s}=0 \\
v_{s}=v_{f / p} & v_{s}=J_{w}
\end{array}
$$

The solute diffusion coefficients, $\mathrm{D}_{\mathrm{s}(\mathrm{f} / \mathrm{ps} / \mathrm{p})}$, in the feed, permeate channels and the porous support layer is set equal to the diffusion coefficient of $\mathrm{NaCl}$ in pure water. It is assumed the porous support layer plays no role in the rejection of the solute. At the outlets of the feed and permeate channel, the solute is assumed to be transport out the model by convention, that is the diffusive transport is considered negligible.

\section{Simulations and Validation}

Simulations were run on a DELL Precision T7500 computer with dual 2.80GHz Xeon processors, 96GB of RAM and Windows 7 operating system. The software used in the simulations was COMSOL Multiphysics versions 5.0 and 5.1. Within the COMSOL environment, the laminar flow node, Darcy's Law node and transport of dilute solute node were used in the simulation.

\subsection{Geometry}

The geometry used in these simulations is shown in Fig. 1. The dimensions were as reported in [27] and [40]. As the thicknesses of the various membrane layers where unavailable, typical values found in the literature were used. It should be noted that the inlet and outlet of the feed channel were extended to mitigate the development of stress concentrations at the entry and exits. Additionally, as the woven fabric layer of the membrane is assumed to play no role in solvent and solute transport, it is treated as being part of the permeate channel.

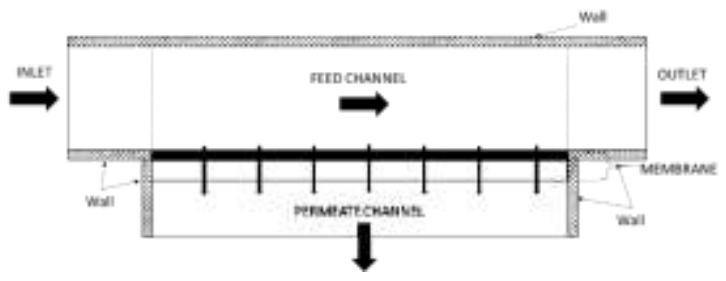

Figure 1: Geometry Used in Simulations

\subsection{Material Properties}

The material properties and dimension used in the simulations are shown in Table 1.

Table 1: Material Properties

\begin{tabular}{lll}
\hline Constant & Units & Value \\
\hline
\end{tabular}




\begin{tabular}{lcc}
\hline$A^{[27]}$ & $\mathrm{m} \mathrm{Pa}^{-1} \mathrm{~s}^{-1}$ & $2.15 \times 10^{-11}$ \\
$\varphi R T$ & $\mathrm{~J} / \mathrm{mol}^{-1}$ & 4988.4 \\
$\rho^{[19]}$ & $\mathrm{kg} \mathrm{m}^{-3}$ & $1.0 \times 10^{3}$ \\
$\mu^{[19]}$ & $\mathrm{Pa} \mathrm{s}^{-1}$ & $0.9 \times 10^{-3}$ \\
$D_{s(f / p / p s)}[41-43]$ & $\mathrm{m}^{2} \mathrm{~s}^{-1}$ & $1.6 \times 10^{-9}$ \\
$L^{[40]}$ & $\mathrm{m}$ & $1.46 \times 10^{-1}$ \\
$h 1^{[44-46]}$ & $\mathrm{m}$ & $5.0 \times 10^{-7}$ \\
$h 2^{[44-46]}$ & $\mathrm{m}$ & $5.0 \times 10^{-5}$ \\
$h 3^{[44-46]}$ & $\mathrm{m}$ & $1.5 \times 10^{-4}$ \\
$h 4^{[40]}$ & $\mathrm{m}$ & $1.73 \times 10^{-3}$ \\
\hline
\end{tabular}

\subsection{Mesh Specification}

The mesh was manually specified for the feed, membrane and permeate channels. Both triangular and quadrilateral elements were used in the mesh. Areas critical to the reverse osmosis process were meshed with a very fine mesh. These included the individual membrane layers and regions just above the membrane. Within the feed channel, an internal boundary was set at a distance of 5\% of the feed channel height, h1, from the feed channel and membrane interface. This was to ensure that a sufficiently small mesh was defined to accurately measure the effects of the concentration polarisation layer [23, 47], while optimising the number of elements for a grid independent mesh.

\subsection{Grid Independence}

Grid impendence was determined based on two criteria: (1) the convergence of outlet parameters to less than $1 \%$ of successive mesh refinements for constant inlet conditions; (2) an increase in the minimum element quality as given within the COMSOL environment. Grid independence was found on a mesh of approximately 6.7 million elements. Fig. 2 shows the convergence of average permeate flow and average permeate concentration for increasing mesh density.

\subsection{Validation}

Simulations were run for the operating conditions as described in Kim \& Hoek [26], who considered three inlet operating pressure $(790 \mathrm{kPa}, 1136 \mathrm{kPa}$ and $1481 \mathrm{kPa})$, for three average feed channel velocities $(0.017$ $\mathrm{m} \mathrm{s}^{-1}, 0.042 \mathrm{~m} \mathrm{~s}^{-1}$ and $\left.0.068 \mathrm{~m} \mathrm{~s}^{-1}\right)$ and three inlet concentrations $\left(10 \mathrm{~mol} \mathrm{~m}^{-3}, 20 \mathrm{~mol} \mathrm{~m}^{-3}\right.$ and $\left.50 \mathrm{~mol} \mathrm{~m}^{-3}\right)$. For these simulations, $D_{s(m)}$ was set to $380.3 \times 10^{-15} \mathrm{~m}^{2} \mathrm{~s}^{-1}$ having been calibrated for one of the experimental data points, $\alpha$ and $\beta$ ranged between -0.176 to 0.038 and -0.197 to 0.072 respectively.

Fig. 3 - 5 compare the simulations results for average permeate flows and permeate concentration versus experimental average permeate flows and permeate concentration. The simulations agreed with the experimental data points. The average predicted error for permeate flow across all simulations was $-0.6 \%$ $\pm 2.6 \%$. The average predicted error for permeate concentration was $0.7 \% \pm 7.6 \%$.

\section{Feed Spacers}

Feed spacers are used to keep the membrane(s) apart from the flow channel. It is therefore practical to assume that the channel height is twice the feed spacer diameter. Similar consideration was given by Amokrane, et al. [48] and Wardeh \& Morvan [33]. In these simulations, the filaments were assumed to be circular with a diameter (D) of $0.865 \mathrm{~mm}$. These filaments were assumed to be completely rigid. The distance between the spacers was determined using the geometrical ratio (G.R.) as defined by [29] and is given by Eq. (9). 


$$
G \cdot R \cdot=\frac{L_{f}}{D}
$$

In the above equation, $\mathrm{L}_{\mathrm{f}}$ is the distance between parallel filaments and $\mathrm{D}$ is the diameter of the filament. It is further noted that the G.R. is typically 7-9 [29]. Using these G.R. values, $L_{f}$ can be estimated and the number of filaments determined. For the length of channel under consideration and G.R. of 7, 8 and 9 correspond to 24, 21 and 19 filaments within the feed channel. The angle between crossing filaments and the flow attack angle were assumed to be $90^{\circ}$. Three (3) spacer configurations were considered: submerged, cavity and zigzag.

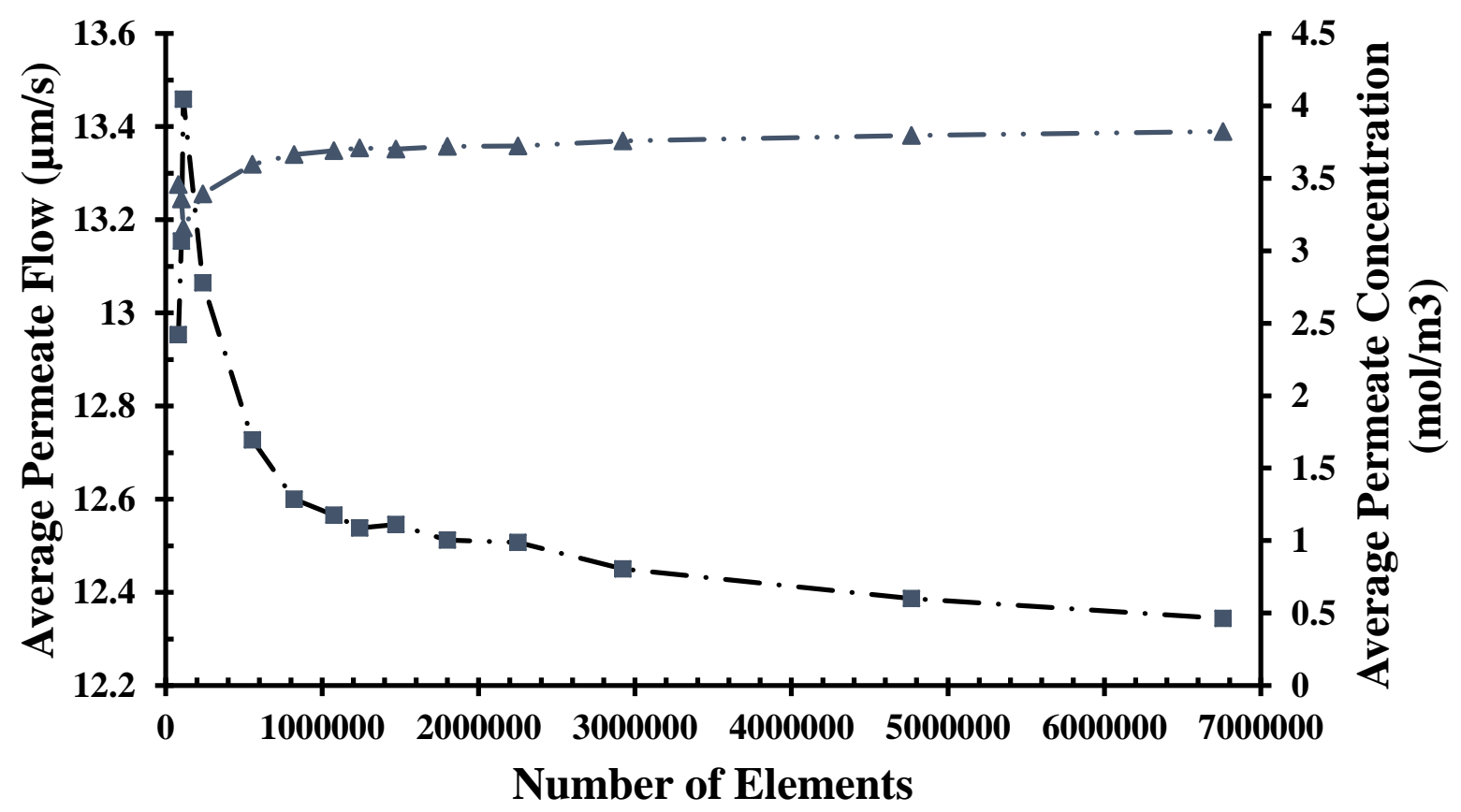

$\rightarrow \cdot$ - Average Permeate Flux $\rightarrow \cdot \cdot$ Average Permeate Concentration

Figure 2: Grid Independence. Boundary and Simulation Conditions: $p_{\text {in }}=1136.3 \mathrm{kPa}, \mathrm{u}_{\text {avg }}=0.042 \mathrm{~m} \mathrm{~s}^{-1}$, $\mathrm{c}_{\text {in }}=50 \mathrm{~mol} \mathrm{~m} \mathrm{~m}^{-3}, \mathrm{D}_{\mathrm{s}(\mathrm{m})}=400.0 \times 10^{-15} \mathrm{~m}^{2} \mathrm{~s}^{-1}, \alpha$ and $\beta=0$ 


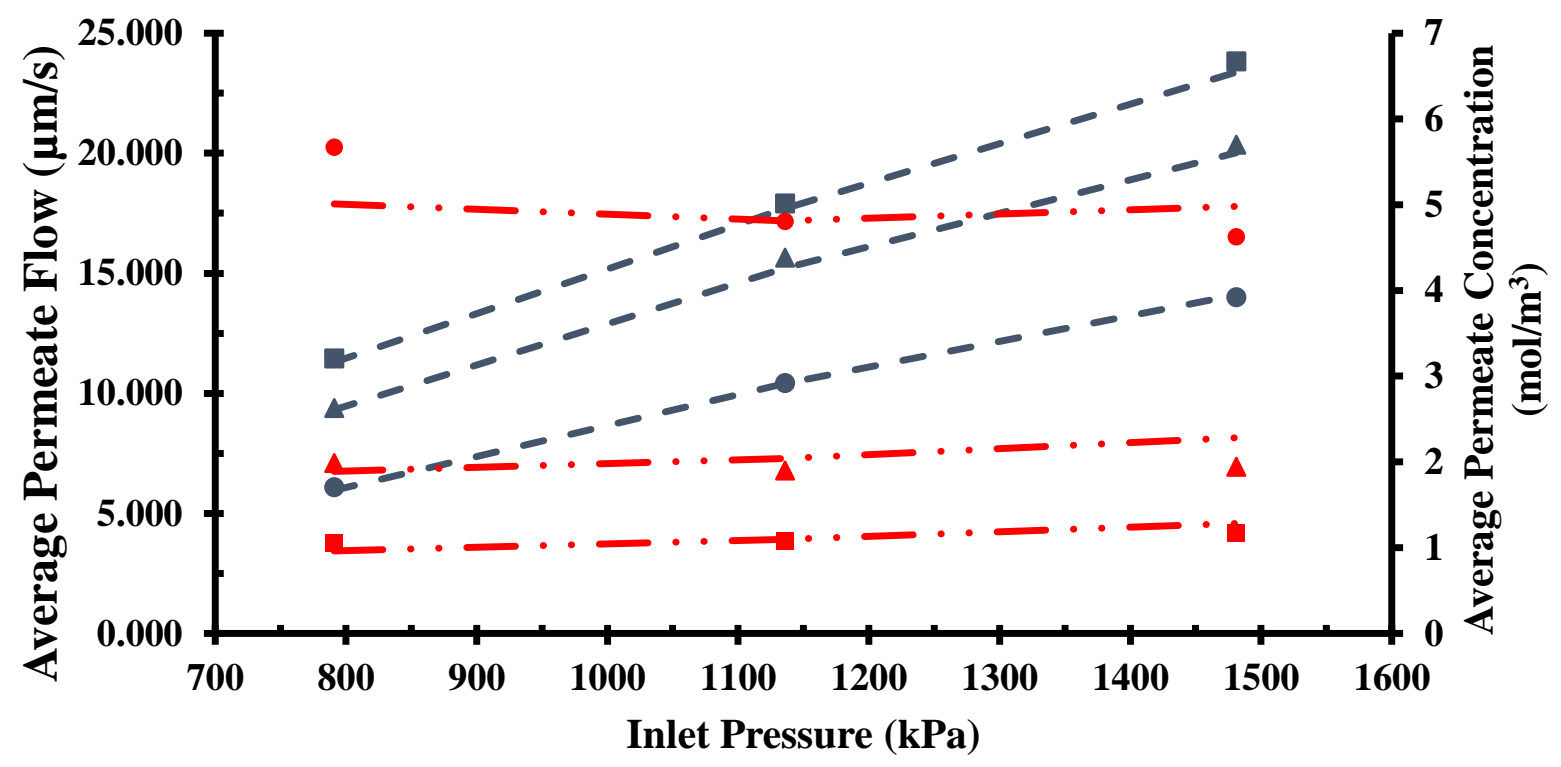

- $10 \mathrm{~mol} / \mathrm{m}^{\wedge} 3$

- $10 \mathrm{~mol} / \mathrm{m}^{\wedge} 3$

$$
\begin{array}{r}
\Delta \quad 20 \mathrm{~mol} / \mathrm{m}^{\wedge} 3 \\
\Delta \quad 20 \mathrm{~mol} / \mathrm{m}^{\wedge} 3
\end{array}
$$

- $50 \mathrm{~mol} / \mathrm{m}^{\wedge} 3$
- Simulations Perm. Flow

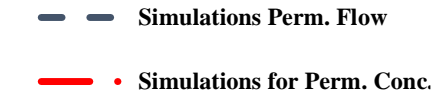

Figure 3: Comparison of Simulated Average Permeate Flows and Permeate Concentration versus Experimental Permeate Flows and Permeate Concentration: Avg. Crossflow Velocity of $0.017 \mathrm{~m} \mathrm{~s}^{-1}$

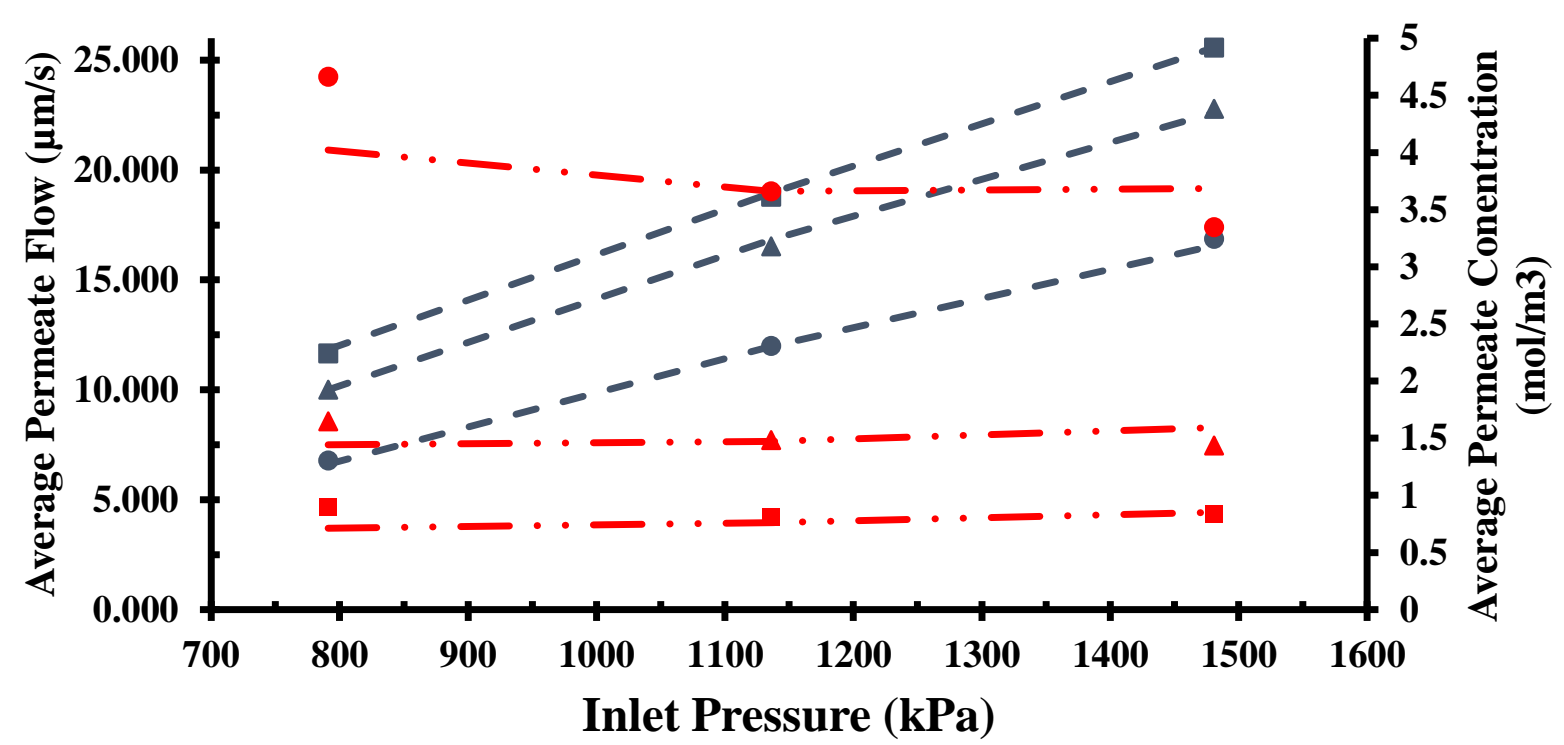
- $10 \mathrm{~mol} / \mathrm{m}^{\wedge} 3$
$\Delta \quad 20 \mathrm{~mol} / \mathrm{m}^{\wedge} 3$
- $50 \mathrm{~mol} / \mathrm{m}^{\wedge} 3$
- Simulations for Perm. Flow
- $\quad 10 \mathrm{~mol} / \mathrm{m}^{\wedge} 3$
$\Delta \quad 20 \mathrm{~mol} / \mathrm{m}^{\wedge} 3$
- $50 \mathrm{~mol} / \mathrm{m}^{\wedge} 3$
- Simulation of Perm. Conc.

Figure 4: Comparison of Simulated Average Permeate Flows and Permeate Concentration versus Experimental Permeate Flows and Permeate Concentration: Avg. Crossflow Velocity of $0.042 \mathrm{~m} \mathrm{~s}^{-1}$ 


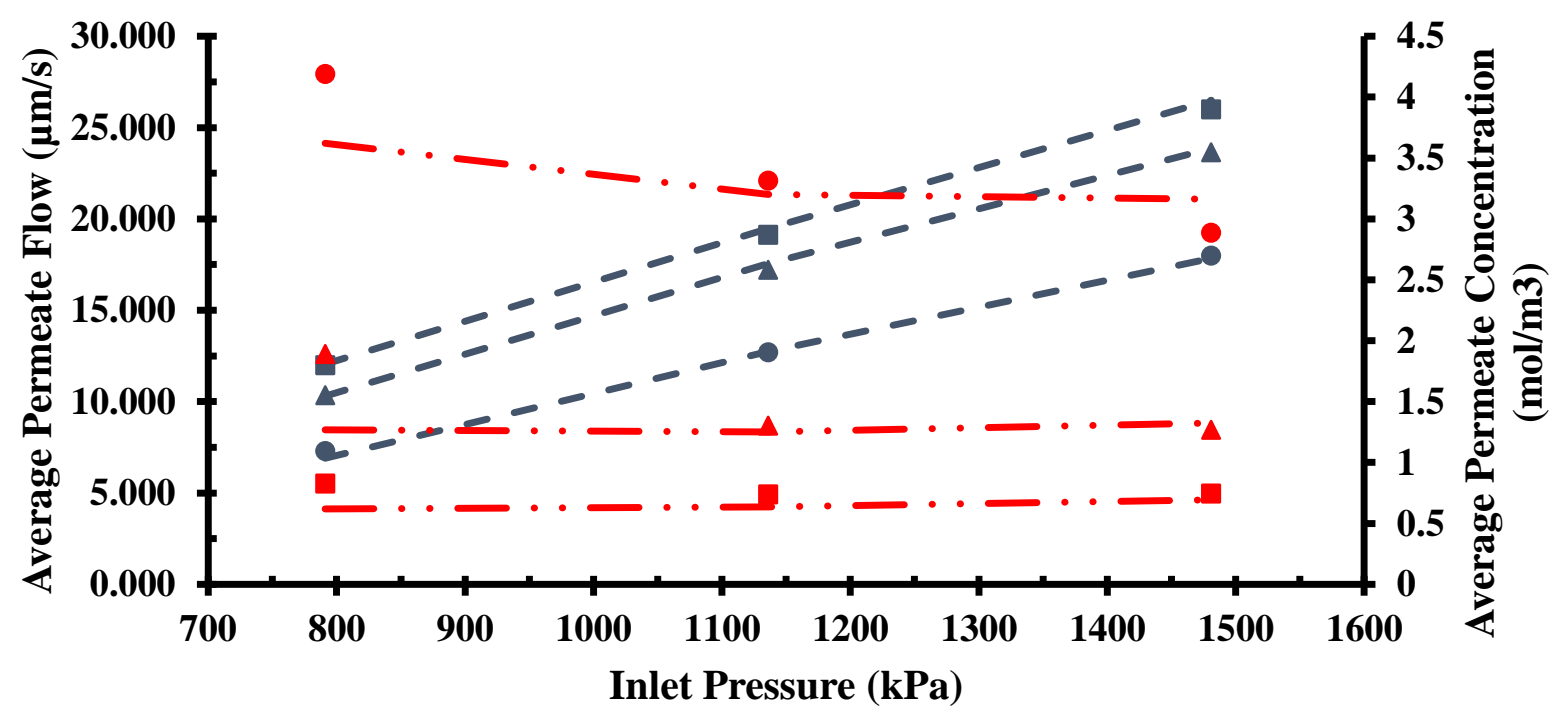

$10 \mathrm{~mol} / \mathrm{m}^{\wedge} 3$
$\square \quad 10 \mathrm{~mol} / \mathrm{m}^{\wedge} 3$

$\Delta \quad 20 \mathrm{~mol} / \mathrm{m}^{\wedge} 3$

- $50 \mathrm{~mol} / \mathrm{m}^{\wedge} 3$

- Simulations for Perm. Flow

$\Delta \quad 20 \mathrm{~mol} / \mathrm{m}^{\wedge} 3$

- $50 \mathrm{~mol} / \mathrm{m}^{\wedge} 3$

- Simulations for Perm. Conc.

Figure 5: Comparison of Simulated Average Permeate Flows and Permeate Concentration versus Experimental Permeate Flows and Permeate Concentration: Avg. Crossflow Velocity of $0.068 \mathrm{~m} \mathrm{~s}^{-1}$

The average permeate flow, average permeate concentration, average feed channel velocity, feed channel pressure losses and maximum wall shear stress for the three spacer types are shown in Table 2. Independent of spacer type, there is an increase in permeate flows across the membrane and a decrease in the average permeate concentration as compared to spacer free channels. The pressure loss across the feed channel increase with the presence of spacers; larger losses seen for submerged types. The submerged spacer type causes a larger pressure loss; cavity and zigzag spacer types have similar losses. Similar pressure pattern losses are reported in the literature [33-34]. Larger wall shear stress is seen for the submerged type spacer than for either cavity or zigzag types. Similar observations are found in the literature [33, 49].

Table 2: Simulation Results for Submerged, Cavity and Zigzag Spacer Types.

\begin{tabular}{|c|c|c|c|c|c|c|}
\hline $\begin{array}{c}\text { Spacer } \\
\text { Type }\end{array}$ & $\begin{array}{c}\text { Geometric } \\
\text { Ratio }\end{array}$ & $\underset{(\mu \mathrm{m} / \mathbf{s})}{\operatorname{Sim} \mathbf{J}_{\mathrm{w}}}$ & $\underset{\left(\mathbf{m o l} / \mathbf{m}^{3}\right)}{\operatorname{Sim} . C_{p}}$ & $\begin{array}{c}\text { Avg. } \\
\text { Channel } \\
\text { Velocity } \\
(\mathbf{m} / \mathbf{s})\end{array}$ & $\begin{array}{l}\text { Feed Channel } \\
\text { Pressure Loss } \\
\quad(\mathbf{P a} / \mathbf{m})\end{array}$ & $\begin{array}{c}\text { Max. Wall } \\
\text { Shear Stress (N } \\
\left.\mathbf{m}^{-2}\right)\end{array}$ \\
\hline No Spacer & $\mathrm{n} / \mathrm{a}$ & 11.97 & 3.738 & 0.0420 & 158.5 & 0.1977 \\
\hline \multirow{3}{*}{ Submerged } & 7 & 13.15 & 3.064 & 0.0453 & 1039.0 & 1.1781 \\
\hline & 8 & 13.03 & 3.128 & 0.0448 & 930.3 & 1.1777 \\
\hline & 9 & 12.92 & 3.187 & 0.0446 & 857.1 & 1.1773 \\
\hline \multirow{3}{*}{ Cavity } & 7 & 13.33 & 3.688 & 0.0426 & 488.7 & 0.2197 \\
\hline & 8 & 13.67 & 3.481 & 0.0422 & 446.6 & 0.2432 \\
\hline & 9 & 13.83 & 3.367 & 0.0419 & 418.0 & 0.2435 \\
\hline \multirow{3}{*}{ Zigzag } & 7 & 14.30 & 3.015 & 0.0427 & 477.8 & 0.5523 \\
\hline & 8 & 14.25 & 3.005 & 0.0422 & 440.6 & 0.5549 \\
\hline & 9 & 14.19 & 2.983 & 0.0419 & 415.5 & 0.5585 \\
\hline
\end{tabular}

Note: Boundary and Simulation Conditions: $\mathrm{p}_{\mathrm{in}}=1136.3 \mathrm{kPa}, \mathrm{u}_{\mathrm{out}}=0.04165 \mathrm{~m} \mathrm{~s}^{-1}, \mathrm{c}_{\mathrm{in}}=50 \mathrm{~mol} \mathrm{~m}^{-3}, \mathrm{D}_{\mathrm{s}(\mathrm{al})}=380.3 \times 10^{-15} \mathrm{~m}^{2} \mathrm{~s}^{-1}, \alpha$ $=-0.0266$ and $\beta=0.0214$. 


\section{Conclusion}

In this paper, the limitations restricting the use of currently available models for the specific application of wave powered desalination were considered. Fully coupled mass-momentum equations were used to describe the hydrodynamics with the feed and permeate channels. Equations were specified to describe for solvent and solute flows across the individual layers comprising thin-film membranes. Additionally, semiempirical relationships were developed to account for the effects of inlet pressure, cross-flow velocity and concentration on solvent and solute flows across the membrane. The model was validated against published experimental data. The predicted errors for simulations of solvent and solute flows were found to be $0.6 \%$ $\pm 2.6 \%$ and $0.7 \% \pm 7.6 \%$ respectively. The effects of three feed spacer types, submerged, cavity and zigzag, on solvent and solute flows were then considered. Key metrics, such as the feed channel pressure loss and maximum wall shear stress at the membrane surface, agreed with the literature.

\section{Acknowledgements}

The authors wish to acknowledge the financial grant provided by BP of Trinidad and Tobago for the conduct of this research.

\section{Nomenclature}
A: Pure Water Permeability Coefficient $\left(\mathrm{m}^{2} \mathrm{~s} \mathrm{~kg}^{-1}\right)$
P: Pressure at Location $\mathrm{x}, \mathrm{y}(\mathrm{Pa})$
B: Salt Permeability Coefficient $(\mathrm{m} / \mathrm{s})$
c: Solute Concentration $\left(\mathrm{mol} \mathrm{m}^{-3}\right)$
$\mathrm{J}_{\mathrm{w}}$ : Permeate Flow through the Membrane $\left(\mathrm{m} \mathrm{s}^{-1}\right)$
h1: Feed Channel Height (m)
h2: Active Layer of Membrane Thickness (m)
R: Universal Gas Constant $(\mathrm{J} / \mathrm{mol} \cdot \mathrm{K})$
Re: Reynolds Number
$\mathrm{Re}_{\mathrm{m}}$ : Modified Reynolds Number
$\mathrm{T}$ : Temperature $(\mathrm{K})$
$\mathrm{u}$ : Transverse Velocity Component $\left(\mathrm{m} \mathrm{s}^{-1}\right)$
h3: Porous Support Layer of Membrane Thickness (m)
$\mathrm{u}_{\text {avg: }}$ : Average Feed Channel Velocity $\left(\mathrm{m} \mathrm{s}^{-1}\right)$
h4: Woven Fabric Layer of Membrane Thickness (m)
$\mathrm{k}$ : Effective Intrinsic Permeability $\left(\mathrm{m}^{2}\right)$
$\mathrm{v}$ : Axial Velocity Component $\left(\mathrm{m} \mathrm{s}^{-1}\right)$
L: Length of the membrane (m)
$\mathrm{x}$ : axial coordinate $(\mathrm{m})$
$\mathrm{y}$ : normal coordinate $(\mathrm{m})$

\section{Subscripts}

m: Active Layer of the Membrane

f: Feed Channel

p: Permeate Channel

ps: Porous Support of the Membrane

b: Bulk Solution

\section{Greek Letters}

$\alpha$ : Semi-Empirical Relationship Affecting Water Flow across Membrane

$\beta$ : Semi-Empirical Relationship Affecting Solute Flow across Membrane

$\mu$ : Absolute Viscosity $\left(\mathrm{Pa} \mathrm{s}^{-1}\right)$

$\rho$ : Density $\left(\mathrm{kg} \mathrm{m}^{-3}\right)$

$v$ : Kinematic Viscosity $\left(\mathrm{m}^{2} \mathrm{~s}\right)$

$\emptyset$ : van't Hoff index

\section{References}

[1] O. Kedem, A. Katchalsky, (1958). Thermodynamic Analysis of the Permeability of Biological Membranes to Non-electrolytes. Biochimica et Biophyhsica Acta, 27, 229-246.

[2] M. Soltanieh, W.N. Gill, (1981). Review of reverse osmosis membranes and transport models. Chemical Engineering Communications, 279-363. 
[3] K. Jamal, M. Khan, M. Kamil, M. (2004). Mathematical modeling of reverse osmosis systems. Desalination, 160(1), 30-31.

[4] Z. Amjal, (1993). Reverse Osmosis: Membrane Technology, Water Chemistry, and Industrial Application. New York: Van Nostrand Reinhold.

[5] A. Alexiadis, D.E. Wiley, A. Vishnoi, R.H. Lee, D.F. Fletcher, J. Bao, (2007). CFD modelling of reverse osmosis membrane flow and validation with experimental results. Desalination, 217(1-3), 242-250.

[6] A.E. Yaroshchuk, (1995). Solution-diffusion-imperfection model revised. Journal of Membrane Science, 101(1-2), 83-87.

[7] S. Álvarez, F.A. Riera, R. Álvarez, J. Coca (1998). Permeation of apple aroma compounds in reverse osmosis. Separation Purification Technology, 14(1-3), 209-220.

[8] M. Kostoglou, A.J. Karabelas (2013). Comprehensive simulation of flat-sheet membrane element performance in steady state desalination, 316, 91-102.

[9] H. Mehdizadeh, K. Molaiee-Nejad, Y. Chong (2005). Modeling of mass transport of aqueous solutions of multi-solute organics through reverse osmosis membranes in case of solute-membrane affinity Part 1. Model development and simulation. Journal of Membrane Science, 267(1-2), 28.

[10] S. Ma, L. Song, S.L. Ong, W.J. Ng (2004). A 2-D streamline upwind Petrov/Galerkin finite element model for concentration polarization in spiral wound reverse osmosis modules. Journal of Membrane Science, 244(1-2), 129-139.

[11] A. Alexiadis, J. Bao, D. Fletcher, D. Wiley, D. Clements (2006). Dynamic response of a high-pressure reverse osmosis membrane simulation to time dependent disturbances. Desalination, 191(1-3), 398.

[12] M. Mulder (1996). Basic Principles of Membrane Technology. Dordrecht: Kluwer Academic Publishers.

[13] D. Paul (2004). Reformulation of the solution-diffusion theory of reverse osmosis. Journal of Membrane Science, 241(2), 372.

[14] W. Zhou, L. Song (2005). Experimental Study of Water and Salt Fluxes through Reverse Osmosis Membranes. Environmental Science Technology, 39(9), 3382-3387

[15] N.G. Voros, Z.B. Maroulis, D. Marinos-Kouris (1996). Salt and water permeability in reverse osmosis membranes. Desalination, 104(3), 141-151.

[16] K. Kezia, J. Lee, A.J. Hill, S.E. Kentish (2013). Convective transport of boron through brackish water reverse osmosis membrane. Journal of Membrane Science, 445, 160-169.

[17] J. Wang, D.S. Dlamini, A.K. Mishra, M.M. Pendergast, M.C. Wong, B.B. Mamba, E..M. Hoek (2014). A critical review of transport through osmotic membranes. Journal of Membrane Science, 454, 516-537.

[18] R.W. Baker, (2004). Membrane technology and its applications (2nd Ed.). Hoboken: John Wiley and Sons.

[19] S.L. Phillips, H. Ozbek, A. Igbene, G. Litton $(1980,11)$. Viscosity of $\mathrm{NaCl}$ and other solutions up to 350" C AND $50 \mathrm{MPa}$ pressures. Berkeley, California, United States of America. Retrieved from http://www.osti.gov/scitech/servlets/purl/6731414/

[20] C.d. Coutinho (2015). A critical view on separation processes by membrane technology applied in vegetable oil refining. In A.K. Pabby, S.S. Rizvi, \& A.M. Sastre (Eds.), Handbook of Membrane Separation: Chemical Pharmaceutical, food, and Biotechnological Applications (pp. 629-663). Boca Raton: CRC Press.

[21] L. Song, S. Yu (1999). Concentration Polarization in Cross-Flow Reverse Osmosis. AIChE Journal, 45(5), 921-928.

[22] A.I. Cavaco Morão, A.M. Brites Alves, V. Geraldes (2008). Concentration polarisation in reverse osmosis/nanofiltration plate-and frame membrane module. Journal of Membrane Science, 325(2), 580.

[23] E. Lyster, Y. Cohen (2007). Numerical study of concentration polarization in a rectangular reverse osmosis membrane channel: Permeate flux variation and hydrodynamic end effects. Journal of Membrane Science, 303(1-2), 140-153.

[24] I. Sutzkover, D. Hasson, R. Semiat (2000). Simple technique for measuring the concentration polarization level in a reverse osmosis system. Desalination, 131(1-3), 117-127. 
[25] R. Rautenbach (1990). Process Design and Optimization. In M. C. Porter, Handbook of industrial membrane technology (pp. 349-354). New Jersey: Noyes Publication.

[26] L. Song (2010). Concentration Polarization in a Narrow Reverse Osmosis Membrane Channel. AIChE Journal, 56(1), 143-149.

[27] S. Kim, E.M. Hoek (2005). Modeling concentration polarization in reverse osmosis processes. Desalination, 186(1-3), 111-128.

[28] W. Yan, Z. Wang, J. Wu, S. Zhao, J. Wang, S. Wang (2016). Enhancing the flux of brackish water TFC RO membrane by improving support surface porosity via a secondary pore-forming method. Journal of Membrane Science, 498, 227-241.

[29] C.P. Koutsou, S.G. Yiantsios, A.J. Karabelas (2007). Direct numerical simulation of flow in spacerfilled channels: Effect of spacer geometrical characteristics. Journal of Membrane Science, 291(1-2), 5369.

[30] S.S. Bucs, A.I. Radu, V. Lavric, J.S. Vrouwenvelder, C. Picioreanu (2014). Effect of different commercial feed spacers on biofouling of reverse osmosis membrane systems: A numerical study. Desalination, 343, 26-37.

[31] O. Kavianipour, G.D Ingram H.B. Vuthaluru (2017) Investigation into the effectiveness of feed spacer configurations for reverse osmosis membrane modules using Computation Fluid Dynamics, Journal of Membrane Science, 526, 156-171.

[32] N.V. Ndinisa, D.E. Wiley, D.F. Fletcher (2005). Computational Fluid Dynamics Simulations of Taylor Bubbles in Tubular Membranes: Model Validation and Application to Laminar Flow Systems. Chemical Engineering Research and Design, 83(1), 40-49.

[33] S. Wardeh, H.P. Morvan (2008). CFD simulations of flow and concentration polarization in spacerfilled channels for application to water desalination. Chemical Engineering Research and Design, 86(10), $1107-1116$.

[34] S. Ma, L. Song (2006). Numerical study on permeate flux enhancement by spacers in a crossflow reverse osmosis channel. Journal of Membrane Science, 284, 102-109

[35] A. Maharajh, P. Persad (2015). A two dimensional CFD steady-state reverse osmosis model using diffusion coefficients. IDA World Congress 2015: Desalination \& Water Reuse (pp. 1-9). San Diego: International Desalination Association.

[36] D. Cheddie, A. Maharajh, A. Ramkhalawan, P. Persad (2010). Transient modeling of wave powered reverse osmosis. Desalination, 260(1-3), 153-160.

[37] H. Schlichting (1979). Boundary-Layer Theory ( $7^{\text {th }}$ Ed.) New York, NY: McGraw-Hill

[38] J. Schwinge, D.E. Wiley, D. F. Fletcher (2002). A CFD study of unsteady flow in narrow spacer-filled channels for spiral-wound membrane modules. Desalination, 146(1-3), 195-201.

[39] C.F. Koutsou, A.J. Karabelas, M. Kostoglou (2018) Fluid Dynamics and Mass Transfer in SpacerFilled Membrane Channels: Effect of Uniform Channel-Gap Reduction Due to Fouling, Fluids, 3(1), 1-20. [40] E.M. Vrijenhoek, S. Hong, M. Elimelech (2001). Influence of membrane surface properties on initial rate of colloidal fouling of reverse osmosis and nanofiltration membranes. Journal of Membrane Science, 188(1), 115-128.

[41] N. Nguyen (2012). Micromiers Fundamentals, Design and Fabrication (2nd Ed.). Oxford: Elsevier.

[42] H. Chen (2013). Modern solid state fermentation: Theory and Practice. Dordrecht: Springer Science.

[43] V.N. Balashov (2012). Diffusion of electrolytes in hydrothermal systems: free solution and porous media. In B. Springer-Science + Business Media, K. Shmulovich, B. W. Yardley, \& G. G. Gonchar (Eds.), Fluids in the crust: Equilibrium and transport properties (p. 227). Dordretch.

[44] L. Lin, C. Feng, R. Lopez, O. Coronell (2016). Identifying facile and accurate methods to measure the thickness of the active layers of thin-film composite membranes - A comparison of seven characterization techniques. Journal of Membrane Science, 498, 167-179.

[45] T. Kamada, T. Ohara, T. Shintani, T., Tsuru, (2014). Optimizing the preparation of multi-layered polyamide membrane via the addition of a co-solvent. Journal of Membrane Science, 453, 489-497. 
[46] E. Drioli, F. Macedonio (2010). Integrated Membrane Systems for Desalination. In K.-V. Peinemann, S.P. Nunes (Eds.), Membrane Tehnology: Membranes for Water Treatment (Vol. 4). Weinheim: WileyVCH Verlag GmbH \& Co. KGaA.

[47] A. Subramani, S. Kim, E.H. Hoek (2006). Pressure, flow, and concentration profiles in open and spacer-filled membrane channels. Journal of Membrane Science, 277(1-2), 7-17.

[48] M. Amokrane, D. Sadaoui, C.P. Koutsou, A.J. Karabelas, M. Dudeck (2015). A study of flow field and concentration polarization evolution in membrane channels with two-dimensional spacers during water desalination. Journal of Membrane Science, 477, 139-150.

[49] J. Schwinge, D. Wiley, D.F. Fletcher (2002) Simulation of the Flow around Spacer Filaments between Narrow Channel Walls. 1. Hydrodynamics, Industrial \& Engineering Chemistry Research, 41, 2977-2987 